\title{
Laboreal
}

Volume $8 \mathrm{~N}^{\circ} 2$ | 2012

A antropotecnologia, ferramenta ou engodo?

\section{Da gestão de riscos à gestão dos recursos da atividade : estudo da resiliência em anestesia pediátrica}

De la gestión de los riesgos a la gestión de los recursos de la actividad: estudio de la resiliencia en el ámbito de la anestesia pediátrica

De la gestion des risques à la gestion des ressources de l'activité : étude de la résilience en anesthésie pédiatrique

From risk management to the activity's resources management : study of resilience in pediatric anesthesia

\section{Lucie Cuvelier}

Tradutor: Adelaide Nascimento

\section{(2) OpenEdition}

Journals

Edição electrónica

URL: http://journals.openedition.org/laboreal/6838

DOI: $10.4000 /$ laboreal.6838

ISSN: 1646-5237

Editora

Universidade do Porto

Refêrencia eletrónica

Lucie Cuvelier, « Da gestão de riscos à gestão dos recursos da atividade : estudo da resiliência em anestesia pediátrica », Laboreal [Online], Volume 8 N² | 2012, posto online no dia 01 dezembro 2012, consultado o 24 setembro 2020. URL : http://journals.openedition.org/laboreal/6838 ; DOI : https:// doi.org/10.4000/laboreal.6838

Este documento foi criado de forma automática no dia 24 setembro 2020.

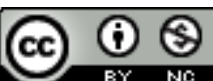

Laboreal está licenciado com uma Licença Creative Commons - Atribuição-NãoComercial 4.0 Internacional. 


\section{Da gestão de riscos à gestão dos recursos da atividade : estudo da resiliência em anestesia pediátrica}

De la gestión de los riesgos a la gestión de los recursos de la actividad : estudio de la resiliencia en el ámbito de la anestesia pediátrica

De la gestion des risques à la gestion des ressources de l'activité : étude de la résilience en anesthésie pédiatrique

From risk management to the activity's resources management : study of resilience in pediatric anesthesia

Lucie Cuvelier

Tradução : Adelaide Nascimento

\section{REFERÊNCIA}

Cuvelier, L. (2011). De la gestion des risques à la gestion des ressources de l'activité. Etude de la résilience en anesthésie pédiatrique. Thèse de Doctorat en Ergonomie. Paris : Conservatoire National des Arts et Métiers.

\section{NOTA DO EDITOR}

Manuscrito recebido em : setembro/2012

Aceite após peritagem : outubro/2012 


\section{Apresentação da tese defendida}

1 Esta pesquisa se inscreve no domínio da fiabilidade dos cuidados médicos e visa a desenvolver uma nova abordagem da segurança dos sistemas: a engenharia da resiliência . A tese defendida é que a resiliência de um sistema, ou seja, sua capacidade de funcionamento em condições variáveis, previstas ou não, reside na capacidade dos operadores em articular a gestão dos riscos para o sistema e a gestão dos seus recursos próprios. Os recursos aqui em questão são não somente os recursos "extrínsecos" aos indivíduos, também chamados "recursos operatórios" e habitualmente utilizados na linguagem comum como "recursos" (isto é, recursos materiais e técnicos, recursos organizacionais, recursos humanos, etc. . Trata-se também de recursos "imateriais", "intrínsecos" aos operadores do sistema e que correspondem aos saberes-fazer, as competências, aos recursos cognitivos, as regras do oficio, aos metaconhecimentos, etc.

\section{Métodos}

Para defender essa tese, três estudos empíricos foram realizados em colaboração com anestesistas pediátricos. Esses estudos visam compreender como estes últimos agem para permitir aos pacientes beneficiar de cuidados nas melhores condições de conforto e de segurança possíveis, apesar dos imprevistos relacionados com a complexidade e a incerteza do funcionamento do corpo humano. Além dos métodos de observação da atividade real, estes estudos apoiam-se sobre técnicas de entrevista (técnica dos incidentes críticos, e técnicas dos protocolos verbais), e sobre análises da atividade em situação de simulação, reproduzindo as funções fisiológicas de uma criança e as reações à anestesia .

\section{Resultados}

O primeiro estudo permite caracterizar os imprevistos e as perturbações que devem ser gerenciadas pelos anestesistas em suas práticas cotidianas. Dois tipos de situação imprevista foram colocadas em evidência :

- as situações "possíveis", que correspondem a ocorrência de eventos que os anestesistas imaginaram a priori como sendo suscetíveis de ocorrer durante a intervenção. Nesses casos, o "imprevisto" não é diretamente ligado ao evento, mas ao momento da ocorrência deste evento que não pode ser determinado previamente pelo médico.

- As situações "impensadas" que correspondem a ocorrência de eventos que nunca foram imaginados pelos anestesistas antes que eles aconteçam. A condição de "imprevisto" é aqui a natureza do evento : a situação surpreende pelo seu decorrer, que não foi imaginado, nesse momento, pela equipe responsável pelo paciente.

Os resultados mostram que a maneira de tratar a situação não é somente relacionada à perturbação em si (frequência, gravidade...), mas dependente sobretudo da antecipação dos operadores em situação real. Os dois estudos posteriores se focalizaram sucessivamente nesses dois tipos de situação imprevista: as situações possíveis e impensadas. 
O segundo estudo se interessa pelos mecanismos de antecipação das situações possíveis pelos anestesistas. O estudo revela que a definição de um envelope de situações possíveis repousa não somente sobre a avaliação de riscos para o paciente, à partir de regras e de conhecimentos gerais do domínio, mas também sobre a avaliação e a gestão dos recursos da equipe de trabalho. 0 objetivo dos anestesistas é na realidade conceber situações ajustadas aos recursos dos diferentes operadores que agem ou agirão em situação. Esta antecipação considera igualmente os recursos do coletivo. Além do mais, esse tipo de gestão visa o domínio da situação à curto termo, mas também o desenvolvimento de recursos à longo termo (formação e auto-formação).

O terceiro estudo é referente a ocorrência, durante a intervenção cirúrgica, de uma "situação impensada". Três modalidades de gestão das situações impensadas foram identificadas: a gestão "determinada", a gestão "prudente" e a gestão "sobrecarregada" :

- A gestão dita "determinada" se caracteriza por um encadeamento rápido das etapas de recuperação da situação e de controle dos riscos à longo prazo, o que permite salvar a vida da criança.

- A gestão "prudente" também garante o sucesso da missão, mas neste caso, as duas etapas de recuperação e de controle da situação não se apresentam imediatamente de maneira sucessiva : um tempo superior a 5 minutos, durante o qual o estado da criança volta a ser estável, é observado entre estas duas ações (recuperação e controle) ;

- A terceira modalidade, dita "sobrecarregada" se caracteriza por um longo tempo de realização da etapa de recuperação da situação (> 9 minutos), o que conduz ao fracasso da missão. Em situação real, a criança não sobreviveria.

7 A análise comparativa da atividade das equipes no simulador, e mais particularmente a análise das comunicações verbais mostra que os três tipos de gestão da situação solicitam recursos cognitivos diferentes. Quando a gestão é determinada ou prudente, as ações realizadas pelas equipes diante das perturbações impensadas visam além do objetivo de gestão imediata dos riscos ligados ao paciente, conservar uma "gestão sustentável" da situação, evitando o acumulo das incompreensões no seio do grupo e adaptando a gestão aos recursos cognitivos dos outros colegas. Pelo contrário, quando a gestão é sobrecarregada, não parece existir uma gestão de longo termo dos recursos cognitivos no seio da equipa.

8 Assim, nas fases de preparação (antecipação das situações possíveis), como na gestão in situ das situações "impensadas", a capacidade do sistema anestésico em ajustar o seu funcionamento para acompanhar as perturbações de forma a assegurar os cuidados do paciente, em condições ideais de segurança - dito de outro modo, a resiliência em anestesia - parece bem residir na capacidade dos operadores em articular a gestão dos riscos vividos pelo paciente e a gestão individual e coletiva dos seus próprios recursos. Ou seja, os resultados indicam que esta gestão de recursos esta relacionada não só com a gestão a curto prazo das situações, mas também com a eficiência a longo prazo do sistema através do desenvolvimento dos recursos da atividade. Aqui, a atividade "produtiva" cotidiana dos operadores tem por objetivo responder aos objetivos da tarefa (permitir o cuidado do paciente) mas ela fornece também oportunidades de desenvolvimento de recursos. 


\section{Conclusão}

Esses resultados permitem por um lado a identificação das condições organizacionais favoráveis a realização dos processos de gestão dos recursos desenvolvidos pelos operadores, e por outro lado, uma proposta de métodos de prevenção de riscos inovadores no campo da segurança dos pacientes, como o sistema de formação através do simulador. Enquanto a gestão de riscos é geralmente abordada em termos de procura de compromissos entre "objetivos de performance" e "objetivos de segurança", a discussão dos resultados convida o leitor a ultrapassar esta oposição clássica através da identificação dos "compromissos de meios", segundo os quais os indivíduos consideram a implicação e o desenvolvimento dos próprios recursos. Enfim, essa mudança de perspectiva nos conduz a questionar os modelos de performance nos quais se inscrevem as démarches de prevenção.

\section{BIBLIOGRAFIA}

Amalberti, R. (1996). La conduite des systèmes à risques. Paris : PUF, Coll. Le travail humain. Bisseret, A., Sebillotte, S., \& Falzon, P. (1999). Techniques pratiques pour l'étude des activités expertes. Toulouse : Octarès-Editions.

Chatigny, C. (2001). Les ressources de l'environnement : au coeur de la construction des savoirs professionnels en situation de travail et de la protection de la santé. Pistes, 3(2). http:// www.pistes.uqam.ca/v3n2/pdf/v3n2a7.pdf

Falzon, P., \& Teiger, C. (1995). Construire l'activité. Performances Humaines \& Techniques, Hors Série (septembre), 34-39.

Hollnagel, E., Woods, D., \& Leveson, N. (2006). Resilience engineering : Concepts and precepts. Aldershot, UK : Ashgate.

Stanton, N. A., Salmon, P., Walker, G. H., Baber, C., \& Jenkins, D. P. (2005). Human Factors Methods-A Practical Guide for Engineering and Design. Aldershot, UK : Ashgate.

\section{AUTORES}

\section{LUCIE CUVELIER}

Université Paris 8

Equipe C3U - Laboratoire Paragraphe - EA 349

2 rue de la liberté - 93526 Saint-Denis, France

lucie.cuvelier@univ-paris8.fr 